\title{
Alternancia política en Comitán, Chiapas: UNA EXPERIENCIA RECIENTE
}

\author{
Flor María Pérez Robledo
}

\section{Introducción}

$\mathrm{E}$ n el marco de los procesos de cambio del sistema político mexicano, este trabajo ${ }^{1}$ intenta recuperar la experiencia de la primera alternancia en el poder municipal de Comitán, ${ }^{2}$ Chiapas, espacio tradicionalmente priísta y cuna de miembros destacados de la clase política de la entidad. Aún cuando existe el consenso de que el municipio es el espacio primario de la democratización del régimen, poco se ha reflexionado sobre las profundas limitaciones materiales y subjetivas que dicho espacio enfrenta para impulsar un proceso endógeno de cambio político de naturaleza democrática. Previa síntesis del comportamiento electoral estatal contemporáneo, que afirma la alternancia política como un hecho real en los distintos niveles de gobierno, el centro de análisis son los procesos electorales en el municipio de estudio.

Las estadísticas confirman que en la elección municipal de 1995 el Partido Revolucionario Institucional, PRI, aunque se impone no consigue el dominio absoluto que ejercía en las elecciones; destaca que el Partido de la Revolución Democrática, PRD, mantuvo una votación cerrada con el partido ganador. En las elecciones de

Flor María Pérez Robledo, egresada de la maestría de Ciencias Sociales, con opción en Estudios Fronterizos, del CESMECA-UNICACH.
1998 los resultados finales dan cuenta de la recuperación del PRI y de una caída importante en los votos del PRD. En las de 2001 las cifras dan el triunfo a una coalición de dos partidos, PRD-PT, hecho que nos permite hablar de la primera alternancia en el poder municipal de Comitán. Sin embargo, en las elecciones municipales de 2004 regresa el PRI al gobierno del municipio. Este cuadro electoral define el último punto del artículo que se presenta, esto es, la dinámica gerencial y política en el gobierno municipal de la alternancia, en tanto convergen variables que explican el regreso del Partido Revolucionario Institucional.

A lo largo del texto, al ir reconstruyendo las percepciones y prácticas de los actores que hacen posible la representación política electoral, una tesis parece quedar clara: la alternancia política como punto de partida para democratizar las instituciones del gobierno local no fue posible porque, si bien hubo cambio de partido en el poder, sus actores jugaron con el viejo formato generador de lógicas facciosas y clientelares y de subordinación al poder gubernamental estatal, que rompen con los principios base de un sistema de partidos. En el contexto del ejercicio gubernativo 2001-2004 se recuperan analíticamente las acciones, prácticas y comportamientos políticos que se alejan de 
las tareas sustantivas que le correspondería realizar a un gobierno de alternancia comprometido con la transición y consolidación democrática del gobierno municipal.

\section{E1 contexto político chiapaneco: las resistencias al cambio democrático}

Algunos estudios han dado cuenta no sólo del subdesarrollo material que sigue caracterizando a la entidad chiapaneca, también de los enormes rezagos que enfrenta en el campo de la política (García, 2003). El dominio casi absoluto del PRI, bajo la aureola del corporativismo del gobierno mexicano que en términos llanos significó poder de control y regulación de las tendencias del cambio social a través del uso y manejo de los recursos públicos, se mantuvo prácticamente intacto hasta los tres primeros años de la década de los noventa. El parteaguas abierto por el proceso electoral de 1988 no se vivió con la intensidad y fuerza que en el plano nacional, los votos por el candidato del PRI a la Presidencia de la República representaron 89.91\% del total, mientras que en el ámbito nacional este porcentaje fue 69.50\% (Gómez, 1990: 228 y 234). El viraje más importante en el campo electoral se va a manifestar a partir de 1994, en una coyuntura política abierta por la irrupción del Ejército Zapatista de Liberación Nacional, EZLN; los saldos de esta coyuntura en las urnas muestran un cuadro político incierto, sujeto a fuertes resistencias y retrocesos e incluso reinstauraciones de viejas prácticas antidemocráticas.

En efecto, al analizar el comportamiento del electorado en los distintos sufragios federales ocurridos entre 1994 y 2000 las expectativas del cambio político democrático resultan modestas, distintas del optimismo de ciertos analistas políticos que en su momento se centraron en algunas de las coyunturas electorales. En 1994 se recordará que Chiapas vivió elecciones federales — presidencia, diputaciones y senaduríasAunque con cifras disminuidas, el PRI ganó la elección presidencial y ocho distritos electorales de un total de nueve. El PRD ganó un distrito, y al alcanzar la primera minoría ganó también una senaduría. Elecciones federales para renovar los poderes legislativos se tuvieron en 1997, los resultados en Chiapas le volvieron a dar el triunfo al PRI: de un total de doce distritos ganó diez, perdiendo dos distritos estratégicos: el xI y el XII, con cabeceras en Tuxtla Gutiérrez y Tapachula, respectivamente, mismos conseguidos por el PRD (García, 2002).

En las elecciones federales de 2000, cuando tuvo lugar la derrota nacional del PRI, el electorado chiapaneco dio de nuevo el triunfo a este partido. De igual manera ganó once diputaciones federales y dos senadurías de mayoría relativa. El optimismo de algunos actores políticos frente a este cuadro electoral federal provenía de la disminución progresiva en el número de los votos ganados por el PRI. Las dos elecciones presidenciales las obtuvo con menos de $50 \%$ del total de votos válidos. Esta percepción se desplaza a las elecciones del legislativo federal, aunque es de enfatizar el hecho real de la pérdida de dos distritos electorales estratégicos en 1997, ganados por el PRD, y un distrito en 2000 conseguido por el Partido de Acción Nacional, PAN.

El comportamiento electoral de los poderes locales resulta más dinámico y más complejo. La elección de 1994 para gobernador la ganó el PRI, no obstante la coyuntura política gestada por el neozapatismo derivó en el relevo del gobernador electo, Eduardo Robledo Rincón, quien permaneció en su cargo por pocos meses. En las elecciones de 2000 Chiapas registra la primera alternancia en la gobernatura, pierde el PRI y gana una coalición de ocho partidos políticos. ${ }^{3}$ El PRI obtuvo 46,68\% del total de votos, $51.50 \%$ la Alianza por Chiapas.

Este optimismo por el cambio político local se desplaza a la lucha por las diputaciones locales y las presidencias municipales; no obstante, en las elecciones de 1995, de un total de 24 distritos electorales locales el 
PRI sólo pierde tres, y de 111 municipios pierde 27. La pluralidad política en el gobierno, amén de las diputaciones plurinominales, estuvo dada en el Congreso local por el PAN y el PRD, y en el campo municipal por prácticamente todos los partidos, en los que fueron distribuidas las 27 alcaldías perdidas por el PRI. En 1998 el comportamiento electoral por los mismos cargos populares mantuvo prácticamente la misma tónica que en la elección anterior. El PRI ganó 21 distritos y 88 alcaldías (García, 2002).

Concluimos este parágrafo reconociendo que las cifras electorales, aunque disminuidas para hablar de una verdadera pluralidad partidista en el sistema de representación política, confirman la alternancia política; se presenta en la gobernatura del Estado, la que mayormente generó grandes expectativas para el electorado chiapaneco. En el imaginario colectivo se había proyectado que desde este cargo se buscaría el equilibrio en la distribución partidista de los cargos populares. Con una elección local en puerta, la de 2001, los partidos que conformaron la Alianza se propusieron repetir la misma fórmula política de coalición para la elección municipal.

\section{El comportamiento electoral en el municipio de Comitán previo a la alternancia}

Los datos electorales anteriores a las elecciones municipales de 1995 dejan en realidad muy poco margen para un análisis exhaustivo sobre el comportamiento del electorado de la sociedad comiteca. En los comicios de 1988, por ejemplo, se registró un conjunto de votos válidos de 22901 que en su totalidad se adjudicaron al PRI. Seis partidos de oposición contendientes no obtuvieron ninguna boleta, hecho nada creible si recordamos que para esas fechas en la cabecera de este municipio ya existían organizaciones de oposición que venían realizando importantes movili- zaciones sociales que ponían de manifiesto su repudio al partido en el poder.

En las elecciones municipales de 1991 los resultados volvieron a ser favorables al PRI, no obstante fue visible una pérdida de credibilidad en la representación política partidista, que hace de las elecciones el fundamento de la lucha y la transmisión del poder político. En este año, de una lista nominal de 36449 electores sólo acudió a las urnas $59.33 \%$, es decir, $40.66 \%$ se abstuvo de hacerlo. Del total de votos válidos, que es igual al total de votos porque no se registraron nulos, $88.28 \%$ correspondieron al PRI, 19094 electores, aunque debe aclararse que los votos al partido ganador sólo representaron $52.38 \%$ del total de los posibles votantes de la lista nominal. Un hecho importante de señalar es que a diferencia de la elección de 1988 donde los partidos de oposición prácticamente no existen, en esta elección se registra al PRD con un número de votos importantes: 2534 , que representan $11.72 \%$ del total de sufragios válidos y el $6.95 \%$ de la lista nominal.

En la elección municipal de 1995 el electorado comiteco manifestó cambios en sus preferencias partidistas, derivados de una coyuntura que cimbró a la sociedad local como conjunto. Tiene tras de sí la crisis socio-política provocada por la irrupción en el escenario público del EZLN, en enero de 1994, y una serie de eventos defensivos protagonizados por la clase dominante articulada al PRI, en tanto que varios de los propietarios afectados por la invasión de ranchos y predios privados en la llamada zona de conflicto, son comitecos o residen en la cabecera municipal de Comitán. La renuncia del gobernador electo, Eduardo Robledo Rincón, a pocos meses de asumir la gobernatura en 1994, y la llegada de políticos interinos y sustitutos nacidos en Comitán, propiciaron sentimientos encontrados al reconocer no sólo la incapacidad de sus políticos para operar sanciones que permitieran restituir el Estado de derecho, sino también la docilidad de éstos ante los mandatos del gobierno federal. 
En el municipio, el PRI tuvo su primer aviso de alarma en las elecciones municipales de 1995, cuando el PRD obtuvo una alta votación en el proceso electoral local y posteriormente en el distrital en la elección de 1997. Ese año los resultados pusieron al descubierto el fenómeno del abstencionismo: de una lista nominal de 46166 electores el total de votos fue 23 112, de tal manera que el abstencionismo del electorado entre la elección previa y ésta pasó de poco más de $40 \%$ a casi $50.0 \%$. La situación visibilizó también la caída estrepitosa del partido oficial, PRI. De obtener $88.28 \%$ del total de votos válidos en 1991 ahora consiguió sólo 49.13\%, 10668 votos. En contraste, el repunte del PRD es prácticamente inédito al obtener $46.34 \%$ del total de los sufragios validados en la elección, 10065 favorables. El PAN, por su parte, hizo su aparición en las preferencias del electorado comiteco con apenas $5.88 \%$ de la votación, 730 votos.

El carácter cerrado de los resultados electorales generó fuertes debates e impugnaciones a los mismos; para una parte importante del electorado comiteco el triunfo le correspondió al PRD, sin embargo, a diferencia de la elección a la gobernatura en 1994 donde ese partido impugnó y logró encabezar importantes movilizaciones en contra de lo que las organizaciones denominaron "fraude electoral", en Comitán sorprendió que este partido no hiciera lo mismo ante una votación tan cerrada. La situación dividió a los perredistas y a los que sin serlo habían apostado por su candidato; éste acusó a los dirigentes del partido de no apoyarlo para pelear el triunfo, reconociendo que la dirigencia municipal "ha hecho de su participación en el partido únicamente un modo de vida", ${ }^{4}$ declaración que tiene de fondo la versión de que la dirigencia del partido había negociado con el PRI, al aceptar de manera fácil su derrota. Después de esta elección el PRD comiteco quedó en una situación de inestabilidad y debilidad, muchos simpatizantes terminaron convencidos de que los dirigentes sólo velan por sus intereses personales, sin importarles los principios y las plataformas político-ideológicas que formalmente sustentan a un partido político ni los intereses de las mayorías.

García, Leyva y Burguete (1998) documentan que en Chiapas el sistema de representación política democrática no ha gozado de buena salud, ello obedece no sólo al ancestral dominio del partido oficial, también a que la disidencia optó por otras vías, siendo una de ellas la configuración de un sistema de organizaciones sociales y populares que con sus estrategias de movilización social lograron modular el comportamiento de los partidos políticos, de tal manera que tuvieran que plegarse a los intereses de las organizaciones. Esta desconfianza hacia los partidos políticos y las instituciones electorales se manifestó después de las elecciones de 1994 en el EZLN y en el movimiento impulsado por éste. De alguna manera la percepción negativa de la vía electoral se generalizó y, en muchos municipios, como en el caso de Comitán, se vivió el regreso fortalecido de las estrategias de movilización, entre ellas la toma de tierras en prácticamente todo el territorio estatal durante los años 1994, 1995 y 1996, como mecanismo privilegiado de presión a los gobiernos federal y estatal (Villafuerte $e t$ al., 1999). En consecuencia, si bien es cierto que los votos obtenidos por el PRD estuvieron prácticamente cercanos a los que obtuvo el PRI, se propició el sentimiento de fraude electoral, pero la acción política no siguió la dirección hacia una impugnación por la vía institucional, sino simplemente el regreso a las estrategias de presión al gobierno en turno. La toma de predios y las movilizaciones sociales exigentes de la satisfacción de demandas de servicios recuperó su centralidad y volvió a desplazar la participación activa de la sociedad local en los procesos electorales sujeta a las normativas establecidas por los órganos electorales.

Durante el ejercicio de gobierno municipal en el periodo 1995-1998, el PRI logró recuperarse, pues contó 
con el apoyo del titular del gobierno estatal, que siendo oriundo de Comitán impulsó la construcción de diversas obras públicas en beneficio del municipio, obras que de alguna manera mejoraron el paisaje urbano y reactivaron al municipio como el centro rector de la región Fronteriza. Sobre estas bases, los resultados de las elecciones municipales de 1998 indican que el PRI logró recuperar una parte importante de los votos perdidos en la elección anterior, lo que le permitió holgadamente seguir gobernando en el municipio de Comitán. En contraste, el PRD registró una caída estrepitosa al perder más de la tercera parte del electorado alcanzado en las elecciones de 1995; a pesar de ello, continuó como segunda fuerza política con 3058 votos obtenidos. El PAN aumentó su votación a 1024 electores. Los resultados de la elección en el distrito para la renovación de las diputaciones del Congreso local fueron muy similares. Otro rasgo visible, además de la recuperación del PRI, es de nueva cuenta el abstencionismo: de una lista nominal de 54178 electores, sólo 32.58\% acudió a las urnas a sufragar su voto, lo que significa que más de $67 \%$ de la ciudadanía no votó.

$\mathrm{El}$ abstencionismo marca y define los términos del triunfo y la derrota electoral. En el caso del PRI, si bien ganó con $70.46 \%$ del total de votos válidos, este triunfo sólo representa $21.75 \%$ del conjunto de electores incluidos en la lista nominal. De igual manera, el PRD se mantuvo como segunda fuerza política, pero sólo con 5.64\% del padrón de electores. Frente al contexto nacional de competencia política definido por las reglas del juego electoral, visible en participaciones altas, tenemos un proceso contrario. En Comitán, aunque no es privativo de este municipio, registramos que entre 1991 y 1995 el abstencionismo pasó de poco más de $40 \%$ a casi $50 \%$, para situarse encima de 67\% en las elecciones de 1998, cifra inédita en el municipio.

\section{La historia de una estrategia de coalición partidaria y el arribo de un gobierno municipal de alternancia}

La contienda electoral por las diputaciones locales y las alcaldías de ya 118 municipios en octubre de 2001 fue un proceso que tuvo particularidades que la hicieron distinta de otras elecciones por los mismos cargos de elección popular. En la mayoría de los municipios y los distritos se siguió una estrategia diseñada desde la capital del estado, centro político del primer gobernador aliancista, quien había optado por repetir la fórmula que le llevó a la gobernatura estatal, esto es, impulsar la coalición partidaria y, en paralelo, la incorporación de una diversidad de organizaciones campesinas, indígenas y urbanas con igual diversidad de demandas y principios político-ideológicos. Esta estrategia, a diferencia de 2000, auguraba éxitos mayores en tanto era promovida desde el mismo centro del poder político. Las razones de instrumentar dicha estrategia derivaron de la situación vivida por el ejecutivo estatal en sus escasos meses en el poder. El peso de los diputados del PRI en el Congreso local y la existencia de un número significativo de alcaldías en manos de priístas dificultaban el proyecto aliancista, siendo vital recuperar el control del Congreso y las presidencias municipales. Comitán es quizá uno de los municipios que visibilizan las luces y sombras de esta estrategia, ahora, "desde el poder".

\section{Los antecedentes inmediatos}

Aunque para la Alianza por Chiapas fue un verdadero desafío conquistar al electorado comiteco, ya que el gobernador priísta había logrado recuperar la confianza de la sociedad hacia su partido; la experiencia aliancista, después del triunfo por la gobernatura, terminó por reposicionar al pequeño grupo que se había responsa- 
bilizado de operar la campaña por la gobernatura en la región Fronteriza, destacando Eduardo Ramírez Aguilar, Javier Ruiz Morales y su hermano, el empresario Rafael Ruiz Morales, este último había sido designado coordinador de la campaña de Pablo Salazar Mendiguchía en la región Fronteriza, con un peso importante en el trabajo de la mesa política de la Alianza porChiapas.

El 20 de agosto de 2000, inmediatamente después del triunfo de Salazar Mendiguchía como nuevo gobernador de Chiapas, en una manifestación frente al palacio municipal de Comitán el ahora ex coordinador regional Rafael Ruiz Morales hizo el anuncio de que en el municipio se asumiría una estrategia similar para las elecciones locales de 2001, declaración que demostraba que el grupo aliancista de Comitán era recompensado por el nuevo gobernador, ya que operó la campaña en el municipio y en la región Fronteriza. De hecho, varios de sus integrantes participaron en la elaboración del Plan de Desarrollo Regional, y algunos fueron llamados a formar parte del nuevo gobierno estatal: Eduardo Ramírez Aguilar asumió el cargo de delegado de Hacienda; Javier Ruiz Morales, titular de la Secretaría de Desarrollo Rural, sDR; y Raúl Abarca Aguilar quedó al frente de la delegación de la SDR en la región Fronteriza.

Resulta importante señalar que hasta el año 2000 los partidos políticos opositores al PRI, con excepción del PRD, ejercían un peso político muy débil en la vida sociopolítica local. El triunfo de la Alianza por Chiapas reposicionó a los partidos políticos de oposición y, por ende, las dirigencias partidistas veían con buenos ojos repetir la experiencia de una alianza, ahora para la alcaldía comiteca. Cifuentes (2004) registra que para febrero de 2001 el PVEM, PRD y PT habían propuesto a Rafael Ruiz como su candidato a presidente municipal; en breve se incorporaría el Partido Convergencia, de tal manera que el destape oficial se realizó el 4 de marzo de ese año, en presencia del nuevo gobernador.
Sin embargo, el premio a la candidatura por la alcaldía comiteca dado a Rafael Ruiz en recompensa por el trabajo dedicado a la campaña de la Alianza por Chiapas, implicaba armar una estrategia para doblegar a la élite política priista y también solventar las tensiones internas de los distintos partidos y actores políticos y sociales que protagonizaban la vida política local. Respecto a lo primero y en un plano más amplio, el nuevo gobernador solicitó al presidente Vicente Fox la necesidad de ejecutar una auditoría a la administración saliente sobre el manejo, uso y comprobación de los recursos del erario público. Adelantándose a ello, el propio gobierno del Estado procedió, sobre todo en el ámbito municipal y en algunas secretarías del gobierno estatal, a la supervisión del manejo de las finanzas públicas de la administración de Roberto Albores Guillén. Esta decisión afectó a muchos políticos priístas de Comitán, quienes habían sido beneficiados con cargos públicos por el ex gobernador.

Para la mayoría de la sociedad comiteca esta acción del nuevo gobierno no perseguía la aplicación de la ley; era, a todas luces, un acto orientado para debilitar al PRI local. El resultado fue no sólo la acción penal ejercida en contra de funcionarios alboristas, ${ }^{5}$ sino lo más importante, la huida de políticos comitecos de su tierra natal y la abstención manifiesta de muchos priístas para participar en una contienda que anunciaba el fracaso del PRI. Despejado el camino, pues con la derrota en la elección presidencial y en la de la gobernatura el PRI vivía su mayor crisis política visible en procesos de fragmentación y luchas internas, la tarea era la construcción real de una alianza, tarea que se vaticinaba sencilla pero que terminó no siéndolo.

En efecto, si bien hubo claridad en la necesidad de derrotar al PRI con una estrategia de poder que de inmediato posibilitara un cambio en la correlación de fuerzas, como lo fue la auditoría a las finanzas públicas que descubrió la corrupción de los funcionarios priístas, esta claridad no existió en torno a los términos de la 
estructuración de la Alianza, sobre todo cuando el propio gobernador anunciaba reiteradamente que la Alianza ya era inexistente y que gobernaba sin partidos. En este contexto bordar una estrategia en la que todos los partidos políticos participantes se sintieran representados implicaba un trabajo político muy fino que los tiempos y el pragmatismo de los operadores de la Alianza por Comitán no estaban dispuesto a emprender.

\section{La construcción de “La Alianza por Comitán”}

El partido más convencido de una coalición partidaria era el Partido del Trabajo, PT, órgano político que al ser el primero en anunciar la Alianza por Chiapas, y ante el triunfo de ésta, ya había obtenido significativos dividendos. Es esta agrupación, previo acuerdo con el futuro candidato y colaboradores del mismo, la que convocó a la formación de una coalición partidaria para la elección municipal de Comitán. En este sentido propuso que, en atención a la fuerza política de cada partido, se asignara la candidatura a la diputación distrital y los puestos claves en el ayuntamiento o puestos administrativos en otras áreas de gobierno local, a cambio de aceptar como candidato a la presidencia municipal a una persona ya ungida desde las altas esferas del poder estatal: Rafael Ruiz Morales (Cifuentes, 2004).

Era evidente que el organismo político de oposición más fuerte en la mayoría de las localidades del municipio de Comitán era el PRD, por lo que gran parte del éxito de la Alianza dependería de este partido y no tanto del PT, quien prácticamente no había alcanzado ningún voto en las elecciones municipales de 1995 y sólo obtuvo 628 votos en la elección municipal de 1998. Los líderes locales del рт asumían decisiones que eran más producto de sus alianzas con el gobierno central y el grupo local aspirante al poder, que de una consulta y diálogo con sus bases, escasas por cierto.
En condiciones similares se encontraba otro partido que tibiamente había manifestado su incorporación a la Alianza por Comitán. Se trataba del Partido de Acción Nacional cuya dirigencia local tenía en realidad poco trabajo con el electorado del municipio, incluso de la propia cabecera. Tanto es así que el PAN no registró voto alguno en las elecciones de ayuntamiento en 1991; en las elecciones municipales de 1995 sólo alcanzó 730 votos y en la elección de 1998 obtuvo 1 024. No obstante, el que formara parte de la Alianza por Comitán era una decisión estratégica para ésta, pues frente al triunfo del PAN en la presidencia nacional se esperaba su reposicionamiento político tanto en el ámbito estatal como en el municipal. A este respecto es interesante destacar el señalamiento de Cifuentes (2004) en el sentido de que en los primeros meses de 2001 Rafael Ruiz, el candidato aliancista comiteco, intentó convencer a la dirigencia panista para apoyar el proyecto, incluso planteando que de las filas del PAN saliera el candidato a diputado local. Después de reuniones múltiples y frente a una actitud de soberbia de la dirigencia, el PAN municipal decidió no entrar a forma parte de la Alianza.

El 27 de febrero de 2001 la dirigencia municipal de cuatro partidos políticos: PRD, PT, PVEM y Convergencia, postuló como candidato único al empresario Rafael Ruiz para contender por la presidencia municipal de Comitán. Sin embargo, en un breve tiempo, el PVEM y el Partido Convergencia desistieron de participar, por lo que la Alianza por Comitán terminó siendo una coalición de dos partidos, PT y PRD. En realidad el PVEM no tenía ninguna representación electoral en el municipio, en las elecciones municipales de 1991, 1995 y de 1998 no había logrado alcanzar ningún sufragio; y aunque en el año 2000 se registró como integrante de la Alianza por Chiapas quedaba claro que su militancia en Comitán era muy precaria. Sin contar con el registro, la dirigencia comiteca del PVEM había decidido participar en la Alianza por Comitán, pero la dirigencia estatal condicionó dicha decisión a que le garantizaran algunas 
regidurías. Frente a la respuesta negativa de los otros partidos y del propio grupo del candidato, el PVEM optó por no formar parte de la Alianza comiteca, integrando su propia planilla aunque con un candidato externo, ex dirigente del PAN. Respecto a Convergencia, la decisión última de no participar en una alianza partidaria tampoco causó ningún impacto, apenas figuraba como una fuerza política local de importancia.

Esta caracterización de los partidos y el comportamiento político activo que los define en el espacio local terminó por colocar al PRD como partido central de la Alianza. En las elecciones municipales de 1991 se impuso como la segunda fuerza política con 2,534 votos; en las elecciones de 1995 vio crecer su popularidad a grado tal que estuvo muy cerca de arrebatarle el triunfo al PRI. Pese a la caída sufrida en las elecciones de 1998 seguía siendo la segunda fuerza política capaz de disputarle el poder al partido tricolor. Además, debe reconocerse que el PRD mantenía lazos estrechos con la mayoría de las organizaciones que se identificaban como independientes. Por lo mismo, frente a una pluralidad de intereses, la estrategia aliancista no era un hecho menor para el PRD municipal.

En el mes de abril de 2001 el PRD cubrió el requisito de celebrar la sesión del Consejo Municipal para aprobar su integración a la alianza partidista y contender bajo la normativa de una coalición. Aún formada ésta en los términos normativos de la ley electoral, en el seno del comité municipal del partido había muchas tensiones que contribuyeron a erosionar el sentido de una verdadera alianza partidaria. El protagonismo que en ese momento alcanzaba el futuro candidato de la Alianza y su equipo de operadores, que en su mayoría no eran perredistas, no residía en la fuerza del PRD ni del otro partido, sino en el apoyo abierto del gobernador aliancista, amén del peso político que el propio aspirante había alcanzado en Comitán y en la región Fronteriza cuando fue coordinador de la Alianza por Chiapas.
En este contexto se generó una corriente disidente formada por una fracción del PRD, Izquierda de Unidad Popular y el Movimiento Popular Comiteco, cuyos integrantes iniciaron campaña en contra del candidato aliancista, pues, en palabras de sus dirigentes, reconocieron que desde tiempo atrás en el espacio público comiteco "ya circulaba la versión de la alianza y del señor Rafael Ruiz como candidato a la presidencia comiteca", un político que en el pasado inmediato no se había acercado a ellos para debatir ideas. Otra versión de los líderes opositores a la alianza reconoce que ya existía un acuerdo cupular entre el aspirante y el entonces presidente municipal del PRD, José Molina Gutiérrez, acuerdo en donde estuvieron ausentes las bases del partido.

Para algunos militantes que se retiraron temporalmente del PRD quedaba claro que la correlación de fuerzas no les era favorable, pues la alianza y el candidato Rafael Ruiz contaban con el apoyo irrestricto de la dirigencia municipal, estatal y nacional del PRD. Esta situación explica, según ellos, el comportamiento un tanto utilitarista del grupo disidente que optó por la presión con el fin de obtener algunas ventajas políticas. Aunque los intentos de negociación se dieron, las tensiones culminaron en una confrontación abierta en donde la disidencia logró conformar una planilla con un precandidato a la alcaldía, convocando a la militancia a no dejarse engañar por la dirigencia del PRD que había actuado fuera de los canales del partido y sus bases, imponiendo un candidato externo, en abierta alusión a Rafael Ruiz. Los acontecimientos posteriores darán cuenta de la fractura de esta disidencia, motivada de alguna manera por el desequilibrio de fuerza entre la dirigencia que favorecía la Alianza y los opositores que postulaban a un candidato interno desprotegido del Comité municipal perredista.

La fracción del PRD que sí formó parte constitutiva de la Alianza fue la de los llamados Hebertos - por reivindicarse seguidores de Heberto Castillolíderes habían participado activamente en el proceso 
electoral del año 2000. Esta fracción del PRD estaba dirigida por varios médicos de la localidad y cuenta con la simpatía de los líderes de algunas organizaciones sociales. Los conflictos de este grupo con la cúpula aliancista se dieron por la candidatura a la diputación del perredista Mario Luis Gómez, quien por los intereses del empresario Rafael Ruiz se mantuvo prácticamente al margen de la campaña de éste. Como era de esperar, el candidato perredista para la diputación local del distrito de Comitán perdió en la elección.

$\mathrm{Al}$ reconstruir la crónica de la campaña tomando en cuenta las percepciones de los actores políticos y ciudadanos de Comitán, se registra que hubo una insistencia discursiva por presentar al candidato de la Alianza como un líder político capaz de atraer por sí mismo no sólo a importantes sectores de la sociedad comiteca sin filiación partidaria, sino también a militantes de partidos políticos cuyas dirigencias habían desdeñado la Alianza. Al igual que en la campaña federal por la presidencia nacional y la de la gobernatura, el discurso político de los aliancistas insistió en el hartazgo de la sociedad hacia el PRI y sus métodos antidemocráticos de ejercer el gobierno. De acuerdo con estos discursos, la atracción hacia el candidato se daba también en los liderazgos y militantes del PRI que habían terminado por romper con su partido. Sin embargo, como comentaron muchos de los entrevistados, la Alianza estaba en manos de los operadores políticos del candidato aliancista y, por consiguiente, al margen de las dirigencias de los dos partidos en coalición.

Los resultados cuantitativos de la elección del 2 de julio de 2001 permiten identificar varios hechos. El primero es un incremento de los electores votantes, 22 778. El segundo hace referencia a que la contienda real se dio prácticamente entre el PRI y la Alianza por Comitán. El tercero es el resultado mismo: el PRI obtuvo 8046 votos contra 8906 obtenidos por la Alianza comiteca. Sin embargo, el PRI impugnó los resultados de numerosas casillas ante el Instituto Estatal Electoral,
IEE. Instituto que acreditó las causales de nulidad en nueve casillas. Los resultados finales variaron, aunque el triunfo de la Alianza fue inevitable: 8156 votos frente a 7552 del PRI, con una diferencia de 604 votos.

Hecho sorprendente fue la alta votación que alcanzó el Partido Acción Social, PAS, que con 2549 estuvo por encima del PAN y el PVEM, aunque ambos partidos registraron también un incremento relativo de votos. El PAN aumentó su votación en más de $67 \%$ respecto a la elección anterior, pues ahora obtuvo 1712 votos; y el PVEM consiguió 1117 , por primera vez registró votación. El candidato y una parte importante de los integrantes de la planilla del PVEM lo formaron líderes y militantes del PRI, quienes se habían inconformado por el método de elección interna de su partido, del mismo modo había disidentes del PAN, hecho que de no ocurrir hubiera colocado a éste como tercera fuerza política. Como señala Cifuentes (2004), con el número de votos obtenidos por estos priístas inconformes hubiera más que sobrado para que el triunfo le correspondiera al PRI.

\section{¿Qué esperaba la sociedad comiteca del nuevo gobierno municipal?}

En un ejercicio de diálogo con la sociedad local y con algunos dirigentes partidistas y de organizaciones sociales, la alternancia en el poder municipal significaba mucho o poco en el futuro inmediato: "este gobierno ya no debe tranzar, tendrá que dejarle algo a la gente"; "va a gobernar distinto a como gobernaba el PRI"; "será un gobierno que impulse la transición a la democracia"; o "creo que va a ser lo mismo que con el PRI", "va a seguir los mismos pasos que el nuevo gobernador". ${ }^{6} \mathrm{La}$ diversidad de expresiones apunta hacia dos posturas: un cambio político de naturaleza democrática, o la continuidad política. En estas definiciones una idea era clara: las expectativas mayores venían de la alternancia en el gobierno estatal, ocurrida en 2000; esta idea esperanzadora no se observó con la 
alternancia en el gobierno del municipio. La razón de ello obedece a que la población y sus actores políticos y sociales vivieron de cerca el proceso de formación de la Alianza por Comitán, en el que se hizo visible los intereses individuales y el uso faccioso del poder partidista por parte de sus dirigentes. En este proceso aliancista estuvo ausente no sólo una propuesta de gobierno definida, también un marco explícito de compromisos entre el gobierno estatal y municipal para encarar los desafíos institucionales que exige un gobierno democrático.

Pero quizá la razón de fondo es que en esta elección local no ocurrió lo que con la elección a la gobernatura en 2000. Detrás de esta última estuvieron desde el inicio de la campaña una diversidad de organizaciones sociales, muchas de ellas con reivindicaciones democráticas en los planos económico, político-institucional y sociocultural. En el caso de la elección municipal, el apoyo de los distintos sectores sociales y sus organizaciones se manejó en clave clientelar, visibilizando la debilidad social al legitimar ésta los excesos del candidato y su grupo que optaron por estrategias del viejo régimen. ${ }^{7}$ Detrás de dicho comportamiento se encuentran las demandas que no van más allá de beneficios a las cúpulas partidistas y demandas básicas de los militantes, entre ellas la de organizaciones que continuaron con la estrategia del voto corporativo.

El balance del ejercicio del gobierno municipal de la alternancia terminó dando la razón a quienes invocaron el pesimismo y la continuidad en el ejercicio gubernativo. Los conflictos fueron recurrentes desde la conformación del gabinete municipal mismo. La administración gerencial y política de la alcaldía estuvo sujeta a fuertes críticas por el carácter autoritario y centralista de la administración, amén de colocar totalmente al margen las plataformas políticoideológicas de los dos partidos formalmente ganadores. El juez de esta experiencia lo será la propia sociedad local, que terminó por calificar este evento de alter- nancia como "una simple derrota electoral del PRI", partido que después de este periodo de gobierno aliancista terminó por convencer al electorado de que su opción política era la mejor. Para los comitecos, el gobierno de la Alianza terminó cuando, a menos de un año de concluir su ejercicio, el presidente municipal se lanzó a disputar otro cargo de elección popular.

\section{La elección municipal de 2004: "Comitán sigue siendo priista"}

A principios de 2004, la administración municipal 20012004 presidida por Rafael Ruiz Morales enfrentaba la exacerbación de las críticas por parte de los actores políticos, de la sociedad local e incluso de quienes inicialmente le habían apoyado. Este balance negativo se afianzó cuando el presidente municipal abandonó sus funciones en marzo del último año de mandato, sin esperar la autorización del Congreso, para dedicarse a los trabajos de la Alianza en el marco regional y distrital, pues aspiraba a una diputación. Eduardo Ramírez, quien desempeñaba el cargo de síndico, fue nombrado presidente interino. ${ }^{8}$

Pese a este balance, las dirigencias de los partidos políticos consideraban que frente a la contienda electoral local a celebrarse en octubre de 2004 era necesario construir acuerdos de convergencia entre los partidos opositores al PRI. Así lo intentaron, desde noviembre de 2003 comenzó a manejarse la posibilidad de formar una coalición partidaria que contendiera en dicho proceso electoral. Sin embargo, como ocurrió en la experiencia anterior, los problemas para llegar a una negociación entre las posiciones fundamentales de cada uno de los partidos con el objetivo de una propuesta común y de un equilibrio en el tratamiento de los problemas centrales del municipio no serían menores.

Nos señala un dirigente partidista que la Alianza para la elección municipal era, como lo había sido la vez anterior, una decisión de "palacio de gobierno". 
Tan es así que los dirigentes de los partidos acusaron al presidente municipal, Rafael Ruiz, de haber destapado como su candidato a José Antonio Aguilar Meza, razón por la cual éstos aceleraron el proceso de selección de otro candidato. En un proceso que no estuvo exento de acusaciones de manipulación, los delegados de las comunidades y de la zona urbana anunciaron que la alianza PRD-PT-PAN elegía como su candidato al médico Armando Cordero Tovar. Sin embargo el conflicto no se hizo esperar. El Movimiento Popular Comiteco y un grupo de perredistas disidentes demandaban que el candidato fuera electo realmente por las bases. Las pugnas al interior continuaron, desbordándose cuando algunos comenzaron a disputarse los cargos de la planilla del ayuntamiento. Cordero Tovar expresó su desconcierto y renunció a la candidatura de la Alianza, aceptando posteriormente ser el candidato del PAN. Este hecho provocó que el PRD y el P'T nombraran a un candidato alterno, el profesor José Luis González Córdova, aunque una fracción del PRD siguió apoyando a Cordero Tovar. ${ }^{9}$ Las tensiones que empezaban a manifestarse propició que los militantes y algunos dirigentes recordaran el fracaso de la Alianza por Comitán y se acusaran entre sí.

Otros actores centrales le darían el toque final a la coalición. Varios líderes campesinos regionales habían expresado su preocupación por el debilitamiento de la alianza PRD-PT, a raíz de la renuncia de Cordero Tovar, y expresaron su temor de que pudiera ganar la contienda el candidato priista, personaje a quien recordaban como "un hombre que está en contra del movimiento social, un enemigo del pueblo". ${ }^{10}$ En este marco, y en palabras de un dirigente de la Organización Campesina "Emiliano Zapata" —Unidad del Movimiento de Organizaciones Independientes, OCEZ- UMOI, se consideraba que Rafael Ruiz había adoptado “actitudes del PRI”, pero que estratégicamente en 2004 de nuevo apoyarían a la Alianza por Comitán pues consideraban importante fortalecer el proceso de alternancia logrado en 2001. Esta postura de apoyo a la Alianza la secundaron los integrantes de la Organización Democrática Independiente de Comitán, oDIC; el Frente de Locatarios Unidos de los Mercados Públicos y Central de Abasto, Frelum; la Organización Campesina "Emiliano Zapata" Democrática Independiente, OCEZ DI; la organización Toj tzotz tze Li Maya; la corriente hebertista del PRD y sectores magisteriales.

La debilidad de las convicciones partidarias y el peso político alcanzado por las organizaciones campesinas y urbanas en el municipio y la región Fronteriza que en aras de obtener beneficios optaron por alternativas de gobierno no democrático, propició que el día 3 de marzo los líderes del PRD, PT, PAN y Convergencia se reunieran y se pronunciaran por Rafael Ruiz como candidato de la coalición para la diputación local por el vi distrito con cabecera en Comitán. Sin embargo, ello no ocurrió con el candidato a la alcaldía comiteca, en donde la alianza fracasó, reduciéndose, como en el anterior sufragio, a una coalición PRD y PT.

¿Qué ocurrió en el seno de la dirigencia del PRI? A diferencia de la contienda electoral, la dirigencia priísta del municipio cerró filas y evitó que las tensiones se desbordaran como en la elección anterior. En el proceso interno para elegir candidato a alcalde se registraron cuatro afiliados: Víctor Manuel Pulido Guillén, Víctor Hugo Ruiz Guillén, Juan Francisco Torres Vera y Jorge Constantino Kánter. Los primeros tres habían participado en los procesos internos anteriores. El día 11 de julio se llevó a cabo la elección priísta para designar a su candidato, resultando ganador Jorge Constantino Kánter con 5078 votos, seguido por Manolo Pulido con 4 006, Ruiz Guillén con 3 959, y para Torres Vera se contabilizaron $1118 .{ }^{11}$ Con los resultados del proceso de selección interna se inconformaron Torres Vera y Manolo Pulido, este último en el mes de agosto registró su candidatura por el PVEM. Cabe recordar que el candidato electo del PRI, Jorge 
Constantino Kánter, era recordado negativamente por militantes de las organizaciones sociales de la región y del estado porque al inicio del conflicto armado de 1994 encabezó las protestas de los ganaderos estatales, llegando incluso a promover los frentes cívicos para la defensa de la propiedad y confrontándose con los diversos actores sociales de la entidad, particularmente con la diócesis de San Cristóbal de Las Casas.

Las campañas transcurrieron entre acusaciones mutuas, particularmente entre los candidatos de la Alianza y del PRI. Los primeros acusaban a los priístas de haber invertido en la compra de votos; los priístas, por su lado, a los de la Alianza por hacer uso de recursos públicos para las campañas de los candidatos aliancistas, no sólo en Comitán sino en todo Chiapas. El día de la elección se informó que el ex gobernador Roberto Albores Guillén había llegado a Comitán para votar y apoyar al candidato de su partido. Los resultados oficiales de la elección a la alcaldía le dieron el triunfo al PRI. Obtuvo 11746 votos; la alianza PRD-PT, 7 671; el PAN, 5 928, y el PVEM 3,601 votos. Los resultados del distrito también favorecieron cómodamente al PRI, con una votación de 26342 votos; en segundo lugar quedó el candidato de la alianza PAN-PRD-PT, con 21 033; le siguió el PVEM, 11118 votos. Para la sociedad comiteca, el hecho de haber perdido la elección de distrito en la contienda por la diputación local por parte del ex presidente era el "castigo" ciudadano por una gestión que no cubrió ni las más mínimas expectativas de quienes le votaron.

\section{La democracia electoral y sus regresiones. Algunas reflexiones}

Una evaluación de los comicios electorales en Chiapas y en el municipio de estudio no puede desconocer que la competencia electoral es ya parte viva de la vida política del estado, como también lo es el peso fundamental que hoy juegan tanto los partidos políticos como los órganos de la representación del electorado. En este marco, la alternancia en los ámbitos de gobiemo federal, estatal y municipal y en los congresos federal y estatal se torna cada vez más en un hecho político recurrente. Sin embargo, a escala municipal la institucionalidad electoral alcanzada no puede ocultar lo que está detrás de los procesos comiciales. La dinámica electoral no está fundada ni en las plataformas o identidades político-ideológicas ni en propuestas de programas de gobierno propio de cada partido político que contiende.

Este vaciamiento de los contenidos formales de los partidos un ideario político ideológico y un proyecto económico-social como plataforma de campaña- fue visible en Comitán en las elecciones de 2001 por la presidencia municipal. Para el ciudadano común ha sido fácil reconocer que en dichos comicios, un líder y su grupo, cuyo antecedente inmediato fue el trabajo cercano que habían realizado en las elecciones del 2000 por el candidato de la Alianza por Chiapas, aprovecharon los registros de dos partidos políticos, PRD y PT, para contender. Quien iba a ser candidato ya estaba decidido desde "arriba", el problema era la construcción de la fachada democrática de dicha elección, siendo visible la relaciones de subordinación de las dirigencias de los partidos respecto a los mandatos del candidato y sus operadores.

Ciertamente los resultados de la elección municipal de 2001 significaron un hecho inédito en la vida política local. De raigambre priísta y cuna de gobernantes del Partido Revolucionario Institucional, Comitán había registrado la derrota de un candidato priista en el ayuntamiento. Este hecho no era desdeñable. La cuarta ciudad más importante del estado entraba a la lista de los municipios que vivían una alternancia y con ello, hipotéticamente, iniciaba un proceso de transición y democratización de su vida política. Sin embargo, el ejercicio real de la administración no cubrió ni las expectativas mínimas de sus votantes. El presidente 
municipal, pese al reclamo de sus gobernados, dejó la alcaldía sin terminar su periodo para contender por una diputación local. El castigo fue claro: en las elecciones de 2004la Alianza fracasó. El triunfo electoral se dio con un amplio margen de votos para el PRI, hecho que fue considerado un fracaso del gobierno aliancista encabezado por el gobernador Pablo Salazar Mendiguchía.

Las lecciones de una experiencia de alternancia, vista desde el plano municipal, entrañan problemas de índole estructural, tanto de las que devienen de las condiciones de atraso económico que impulsan una cultura política clientelar y faccionalista, como de las que derivan de una falta de institucionalidad democrática en las relaciones entre la federación y los estados, y entre éstos y el municipio. En un contexto con tales características, donde la recurrente desprotección social es la fuente que termina por alimentar una cultura política antidemocrática que erosiona los valores puntales de una ciudadanía (Lomnitz, 2000), resulta prácticamente imposible la construcción de una ciudadanía capaz de impulsar espacios colectivos y esferas públicas de diálogo, deliberación y acción política relativamente distante de las instituciones políticas formales, como lo postulan los teóricos que evalúan la calidad de la democracia.

En Comitán, las organizaciones campesinas, indígenas o populares, si bien llegan a sobreponerse al poder partidista como lo constatan para la región y el estado García, Leyva y Burguete (1998), no ocurre lo mismo respecto al poder de algunas instituciones de gobierno y a las figuras de los gobernantes. Las organizaciones populares siguen siendo estado-céntricas (Zermeño, 1996). Al igual que los partidos políticos, las organizaciones sociales tampoco pretenden impulsar formas de participación política democrática; siguen invocando una lucha política entre la oposición —a la que dicen pertenecer - y el sistema dominante, cuando esta ecuación ya ha sido desmembrada. A final de cuentas, la acción política de las organizaciones populares termina por arroparse en el utilitarismo contingencial de la dirigencia y sus bases, aunque ello implique optar por alternativas de gobierno no democráticas. Los ideales de una democracia con la participación responsable de la sociedad que decantaría en foros públicos deliberativos (Habermas, 1993; Arendt, 2001) sigue siendo una tarea por construir, aunque se antoja más utópica que real.

Como señala Guillén (1993), la alternancia trae consigo tareas fundacionales, no obstante, el problema inmediato que es posible identificar es la incapacidad de los actores políticos para construir acuerdos entre los partidos que deciden coaligarse en las contiendas electorales. Si no se dan estos acuerdos difícilmente habrá propuestas que se traduzcan en políticas públicas reales desplegadas en una administración de gobierno. La ausencia de estos acuerdos posibilita no sólo el retorno del PRI, como ocurrió en Comitán, sino el desarrollo de una dinámica gobernativa dominada por la fragilidad institucional, y aún cuando sea visible el castigo de los electores a gobernantes que no cumplieron con sus expectativas, este castigo no necesariamente se traduce en cambios reales en las políticas públicas. En dichos términos, el desafío en el espacio de gobierno municipal es la construcción de una ciudadanía real que además de imprimir el sentido democrático a sus prácticas y acciones colectivas y castigar con el retiro del voto a los malos gobernantes, sea capaz de exigir y presionar a los actores políticos en el poder para que rompan con prácticas que por décadas sustentaron un ejercicio y una práctica de gobierno sustentado en la impunidad y la lealtad al gobernador en turno, de esta manera podrán abrirse a la rendición de cuentas y a la participación ciudadana. 


\section{Notas}

${ }^{1} \mathrm{El}$ presente artículo fue realizado a partir de uno de los capítulos de la tesis "Formas de acción colectiva y participación política en Comitán, Chiapas", presentada en noviembre de 2005 en la maestría de Ciencias Sociales, opción en Estudios Fronterizos, del Centro de Estudios Superiores de México y Centroamérica de la UNICACH.

${ }^{2}$ El municipio de Comitán se ubica a 163 kilómetros de Tuxtla Gutiérrez, la capital, y a 90 kilómetros de la frontera con Guatemala, siendo el centro más importante de la región Fronteriza, misma que también integran los municipios de Las Margaritas, Frontera Comalapa, La Independencia, Chicomuselo, Socoltenango, Tzimol y Maravilla Tenejapa.

${ }^{3}$ La coalición estaba formada por PRD, PAN, PT, PVEM y Convergencia por la Democracia, Partido del Centro Democrático, Partido de la Sociedad Nacionalista y Partido Alianza Social.

${ }^{4}$ Entrevista con el médico Roberto Gómez Alfaro. Abril de 2004.

${ }^{5}$ Fueron, entre otros, los casos de los priistas Adolfo Argüello Mandujano e Ismael Delfín Cristiani, quienes abandonaron el estado. Un caso más dramático se dio para el doctor Francisco Humberto Córdova Cordero, a quien le iniciaron dos procedimientos administrativos, imponiéndosele una sanción económica e inhabilitación para ejercer cargos públicos, amén de su encierro temporal en el penal de Cerro Hueco.

${ }^{6}$ Estas expresiones fueron retomadas de entrevistas y conversaciones informales sostenidas con población de la ciudad, durante el periodo posterior a la elección municipal de octubre de 2001.

${ }^{7}$ La debilidad estatal y su necesidad de mediaciones exitosas han hecho del caciquismo y de la relación clientelar que se establece entre el cacique y la población y/o sus organizaciones, piezas clave no sólo para la transmisión de las consignas y proyectos del partido y del gobierno al pueblo, sino también para legitimar al partido gobernante y a las autoridades del estado. El faccionalismo, entendido como un grupo de hombres fieles a un jefe cuyo objetivo principal es obtener ventajas y privilegios, guarda estrecha relación con el fenómeno del caciquismo, en tanto la reproducción de este último también deriva de la capacidad de sus integrantes para beneficiar a sus fieles, además de proporcionar los contactos con las masas a la facción a la que pertenece (véase De la Peña, 1993, Tapia Santamaría, 1992; Bobbio y Viroli, 2002).
${ }^{8}$ Diario ElMundo, 13 de marzo 2004. Comitán, Chiapas.

${ }^{9}$ Diario ElMundo, 24 de junio de 2004.

${ }^{10}$ Entrevista con un dirigente de la OCEZ DI, septiembre de 2004.

${ }^{11}$ Diario Nuevo Milenio, 12 de julio de 2004. Comitán, Chiapas.

\section{Bibliografía}

Arendt, Ana, 2001, La condición bumana, Paidós, Barcelona.

Bobbio, Norberto y Viroli, Mauricio, 2002, Diálogo en torno a la República, Tusquets editores, España.

Cifuentes, Disraelí E. Ángel, 2004, Transición politica en Comitán, editorial Nuevo Milenio, Comitán, Chiapas, México.

De la Peña, Sergio, 1993, "Poder local, poder regional: perspectivas socio-antropológicas", en Padúa, Jorge y Vanneph, Alain (compiladores), Poder local, poder regional, El Colegio de México-CEMCA, México, pp. 27-56.

García, María del Carmen, Xochitl Leyva y Araceli Burguete, 1998, "Las organizaciones campesinas e indígenas de Chiapas frente a la reforma del Estado: una radiografía", en Cuadernos Agrarios 16, nueva época, México, pp. 75-94.

García Aguilar, María del Carmen, 2002, "Reformas electorales, partidos políticos y elecciones. Luces y sombras de la democracia en Chiapas", Anuario 2000, CESMECA-UNICACH, Tuxtla Gutiérrez, México, pp. 11-86.

—, 2003, "Política y sociedad en Chiapas 1970-2000. Las utopías, los intereses y las realidades", Tesis para optar por el grado de doctora en Ciencias Sociales, División de Ciencias Sociales y Humanidades, UAM-Xochimilco, México.

Gómez Tagle, Silvia, 1990, Las estadísticas electorales de la reforma política, Cuadernos del CEs, El Colegio de México, México.

Guillén López, Tonatiuh. 1993, Baja California 1989-1992, Alternancia politica y transición democrática, El Colegio de la Frontera Norte, $\mathrm{CIH} /$ unAm, México.

Habermas, Jürgen, 1993, Teoría de la acción comunicativa: complementos y estudios previos, Red Editorial Iberoamericana, México.

Lomnitz, Claudio, 2000, “La construcción de la ciudadanía en México, Metapolítica, volumen 4, julio/septiembre, 2000, México, pp. 128-149.

Tapia Santamaría, Jesús (coord.), 1992, Intermediación social y procesos politicos en Michoacán, El Colegio de Michoacán, México.

Villafuerte Solís, Daniel, Salvador Meza Díaz, Gabriel Ascencio Franco, María del Carmen García Aguilar, Carolina Rivera 
Farfán, Miguel Lisbona Guillén y Jesús Morales, 1999, La tierra en Chiapas. Viejos problemas nuevos, UNICACH, Plaza y Valdés, Villafuerte et al., 1999.

Zermeño, Sergio, 1996, La sociedad derrotada. El desorden mexicano de fin de siglo, Universidad Autónoma de México/Siglo Xxi, México.

—, 2005, La desmodernidad mexicana y las alternativas de la violencia y la exclusión en nuestros días, editorial Océano, México.

\section{Documentos}

Agenda Estadística Chiapas, 1989, sPP, gobierno del Estado de Chiapas.

IEE, Resultados de las elecciones municipales en Comitán y en los municipios de la región fronteriza, 2001.
IEE, Resultados de las elecciones municipales en Comitán y en los municipios de la región fronteriza, 2004.

\section{Hemerografía}

Diario ElMundo, 13 de marzo de 2004, Comitán, Chiapas. Diario ElMundo, 24 de junio de 2004, Comitán, Chiapas.

Diario Nuevo Milenio, 12 de julio de 2004, Comitán, Chiapas.

\section{Páginas de Internet}

http:cee-chiapas.org.mx/estadísticas/ayum91.htm http:cee-chiapas.org.mx/estadísticas/ayum $95 . h t m$ http:cee-chiapas.org.mx/estadísticas/ayum98.htm 